\title{
JOURNAL.RU
}

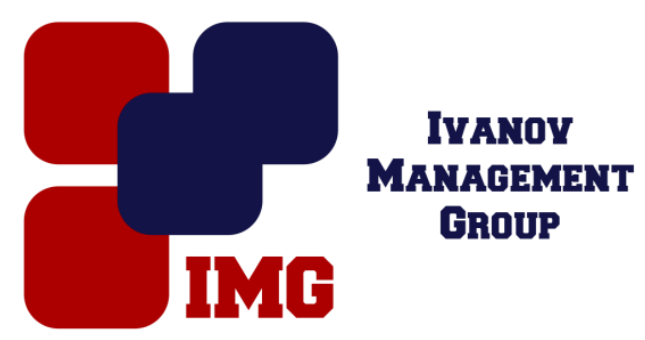

\author{
Дробышевская Л.Н., Орел О.И. \\ Кубанский государственный университет \\ Краснодар, Россия
}

doi: $10.18411 / 1 \mathrm{j}-31-05-2017-58$

idsp 000001:1j-31-05-2017-58

\section{Управление экономической безопасностью предприятий электроэнергетического комплекса}

\begin{abstract}
Аннотация
Данная статья посвящена исследованию теоретических основ управления экономической безопасности электроэнергетического комплекса. В результате анализа было определено ее места в системе национальной безопасности. Также были определены основные проблемы в реформирование электроэнергетического комплекса России.

Ключевые слова: экономическая безопасность, электроэнергетика, электроэнергетический комплекс, энергетическая безопасность, реформирование электроэнергетики, государственное регулирование электроэнергетики

Практика последних десятилетий показала увеличение интереса к экономической и энергетической безопасности. Электроэнергетический комплекс имеет сложную систему экономических отношений между своими субъектами Проблемы истощения запасов энергоресурсов и постоянное возрастание количества потребляемого топлива создает уразы для его безопасности. Кроме того, текущее положение переходного периода электроэнергетики создает угрозу стабильного функционирования электроэнергетического комплекса. В этом контексте вопрос экономической защищенности электроэнергетического комплекса от воздействия негативного влияния факторов внешней и внутренней среды приобретает еще бо́льшую значимость [5].
\end{abstract}


Как известно, под экономической безопасностью понимается состояние экономики, которое характеризуется поступательным экономическим ростом, качественным удовлетворением потребностей общества, высокой степенью защищенности к воздействию негативного влияния факторов внутренней и внешней сред [1].

Состояние топливно-энергетического комплекса (ТЭК) определяет уровень энергетической безопасности в стране. В современном обществе развитый и отлаженно функционирующий ТЭК является основой благополучия системы социальных, экономических и политических отношений России, а также показателем эффективности государственного управления.

Впервые понятие энергетической безопасности было введено в 1947 г. в законе США, регламентирующим действия государства в сфере национальной безопасности[3]. Для того чтобы определить место энергетической безопасности в общей структуре национальной экономики необходимо акцентировать внимание на динамично происходящих изменениях внутренней и внешней сред, a также на тесной связи между сферами экономики. Данный факт свидетельствует о невозможности полного разделения понятий экономической, национальной и энергетической безопасности, поскольку существует сложный процесс корреляции всех сфер, а, следовательно, и видов безопасности общества. Каждый из рассматриваемых видов безопасности является структурным элементом другого, и в зависимости от изменения среды пребывания усиливать или ослабевать свое влияние [8].

Подводя итог сказанному, можно говорить, об энергетической безопасности как о динамической категории, характеризующей такое состояние сбалансированности ТЭК, при котором возможно надежное обеспечение данным комплексом потребности экономики страны в топливно-энергетических ресурсах надлежащего качества и в необходимом объеме, а также способность противодействовать постоянному влияние внутренних и внешних угроз [8].

Электроэнергетика - это составная часть ТЭК, являющаяся базовой отраслью экономики Российской Федерации. Она относится к естественным монополиям, вследствие чего определяет стабильность развития экономики страны. Предприятия энергетического комплекса производят большую долю валового внутреннего продукта. Электроэнергетический комплекс занимается генерацией, передачей и продажей двух товаров: электроэнергии и мощности.

Проведя анализ категорий «электроэнергетика» и «экономическая безопасность», перейдем к трактовке понимания термина «экономическая 
безопасность электроэнергетического комплекса». На наш взгляд, экономическая безопасность электроэнергетического комплекса - это такое состояние сбалансированности электроэнергетики, при котором обеспечивается высокая степень защищенности к воздействию влияния факторов внутренней и внешней сред комплекса, значительный уровень показателей экономического роста объектов электроэнергетической деятельности, полное обеспечение национальных потребностей в товарах (электроэнергии и мощности) данного комплекса.

В конце XX в.в развитии электроэнергетического комплекса встал вопрос о необходимости изменения базовых принципов ее устройства. Мировая практика показывает неэффективность существующего централизованного управления отрасли. Либерализация электроэнергетики рассматривалась как выход из проблемного положения, поскольку превалировало мнение о том, что управление частной собственностью проще, чем государственной и общественной. Началось реформирование отрасли с дерегулирования, перехода от вертикально-интегрированных структур к конкурентному рынку электроэнергии.

Важной особенностью функционирования электроэнергетического комплекса является одновременное присутствие в нем секторов естественных монополий и потенциально рыночной конкуренции. Следовательно, главным вопросом обеспечения экономической безопасности становится создание благоприятных условий для функционирования электроэнергетики как целостной системы независимо от принадлежности ее звеньев к разным рыночным структурам [3].

В настоящее время вРоссии вопросу правового регулирования электроэнергетики уделяется большое внимание. Государственная политика в области электроэнергетического комплекса нацелена на завершение процесса переходного периода в реформировании отрасли. В основе реструктуризации электроэнергетики лежит модель рыночной экономики. Законодательная база комплекса представлена рядом нормативно-правовых актов, в число которых входят федеральные законы, постановления правительства, подзаконные акты, регулирующие разнообразные отношения в данной сфере [2].

Процесс перехода электроэнергетического комплекса России к рыночному регулированию можно условно разделить на несколько этапов:

- трансформация всей экономической системы России, переход к рыночному регулированию, приватизация предприятий 
электроэнергетики и создание РАО «ЕЭС России» (конец 1980-х начало 1990-х гг.);

- начало реформы отросли, создание оптового рынка электроэнергии и мощности (середина 1990-х - начало 2000-х гг.);

- спад темпов реформирования из-за кризиса, преодоление его и дальнейшая реструктуризация отросли (2008 г. - настоящие время).

В начале XX в. началась коренная перестройка электроэнергетики, в основе которой лежал успешный опыт зарубежных стран. Реструктуризация отрасли должна была стимулировать увеличение инвестиционной привлекательности предприятий комплекса, создать условия для саморегулирования электроэнергетики с одновременным снижением государственного влияния. Отметим положительные моменты в реформирования отрасли:

- результативная программа приватизации государственных электроэнергетических компаний, которая помогла отдать конкурентному рынку большую часть тепловой генерации, привлечение частных инвестиций в электроэнергетику через продажу эмиссионных ценных бумаг;

- введение экспериментальной методики долгосрочного торфообразования в сетевых компаниях на примере успешного зарубежного опыта, RAРрегулирования дает стимул для снижения издержек производственного процесса;

В то же время нельзя не отметить и негативные моменты в реформировании системы электроэнергетического комплекса.В первую очередь отметим, что намеченная модель реформирования не получила всеобщего одобрения. Несмотря на то, что отрасль уже претерпела значительные изменения в процессе перехода к конкурентному рынку, достаточно часто предпринимаются попытки возврата к централизовано регулируемой системе комплекса. Созданная в результате массовой приватизации компаний рыночная конкурентная структура электроэнергетики подвержена негативному вмешательству в ее равновесие. Массовое слияние энергетических компаний создает крупных игроков на рынке, которые используют свое влияние для манипулирования ревностными ценами. Кроме того, в действующей системе отношений лишь очень узкий сегмент рынка имеет рыночное конкурентное регулирование [7]. 
Во-вторых, существует ряд недостатков в организации самой системы функционирования рынков электроэнергии и мощности:созданная модель функционирования ОРЭМ обладает достаточно низким уровнем свободной конкуренции;оказывается большое внешнее давление на свободное ценообразование путем введения ограничений на подачу заявок, а также через административные механизмы;из-за устаревшего оборудования сектор тепловой генерации оказался недостаточно конкурентоспособным, что привело к недозагрузке его мощностей и как следствие отрицательным финансовым показателям компаний;рынок услуг электроэнергетического комплекса остается недоработанным, из-за чего деятельность инфраструктурных компаний компенсируется не в полном объеме;огромная вынужденная сегментация рынка мощности не позволят использовать в нем конкурентное регулирование;слабая связь развития электроэнергетики с концепцией национальной инновационной системы;непроработанный механизм инвестирования в модернизацию генерирующего оборудования, которое находится в состояние критического износа.

Третьей важной проблемой в эффективности проводимых реформ является неотлаженная система государственного регулирования электроэнергетического комплекса, которая недостаточно адаптирована для работы в рыночной конкуренции. Очевидно, что в стратегии развития любого государства одним из направлений является переход к экономически и энергетически безопасному стабильному развитию. Вопросы, связанные с правовым регулированием оптовых и розничных рынков в электроэнергетике Российской Федерации, крайне важны.

Важным вопросом в государственном регулировании деятельности электроэнергетического комплекса является контроль над соблюдением антимонопольного законодательства. Субъектам электроэнергетического комплекса России свойственно объединение их в холдинги с широкой зоной влияния. В качестве объектов антимонопольного регулирования выступают отношения по продаже крупных пакетов акций энергетических компаний и долей в уставном капитале, контроль над сговором и согласованными действия между участниками электроэнергетического рынка, уровень присутствия энергетических компаний на оптовом рынке, а также цены и тарифы на электроэнергию. Целью антимонопольного регулирования является превентивное предупреждение нарушений в действиях участников рынков электроэнергии и поддержка конкурентных отношений участников рынка. В 
качестве полномочий ФАС России по обеспечению экономической безопасности электроэнергетики выступает:

- контроль над экономической концентрацией и согласование сделок;

- определение признаков нарушение антимонопольного законодательства участниками рынка;

- установление ограничений в ценовых заявках;

- принятие карательных мер при неоднократном нарушении законодательства [2].

В системе рыночных отношений отсутствуют механизмы конкурентного влияния потребителей на поставщиков электроэнергии, вследствие чего происходит ежегодный необоснованный рост тарифов. Подобная неэффективная система снижает позиции российских энергетических компаний на международной арене. Кроме того, все методы в регулировании направлены на решение краткосрочных оперативных проблем комплекса, в которых не заложены фундаментальные экономические принципы. К основным пробелам законодательства можно отнести неэффективность антимонопольного регулирования электроэнергетики и отсутствие изменений в организации конкурентно ориентированного тарифного регулирования [4].

Четвертая группа проблем посвящена системе стратегического развития и управления электроэнергетики. Трансплантируя опыт рыночного регулирования электроэнергетического комплекса развитых стран, организаторы не реализовали систему управления перспективным развитием отрасли. Отсутствие региональных институтов по исследованию положения дел в отрасли и разработке инвестиционных программ с увязкой на перспективное развитие создают существенную неопределённость по ряду ключевых показателей:необходимого уровня балансовой и сетевой надёжности;оснащение вводов ресурсами газа;предполагаемого объема инвестиций в развитие комплекса [6].

В Российской Федерации отсутствует орган управления, в компетенцию которого входили бы вопросы перспективного развития электроэнергетики вследствие чего данную обязанность возложил на себя системный оператор, основной обязанностью которого является оперативно-диспетчерское управление. Однако руководствуясь своим основным принципом «спрос должен быть удовлетворен любой ценой», закладывает в прогнозный баланс потребления завышенные показатели, что в конечном итоге создает излишние издержки производства. Далее применение принципа трансляции в 
ценообразовании перекладывает все эти сверхзатраты на тарифы конечных потребителей, увеличивая стоимость купленной электроэнергии. Данный факт свидетельствует о некомпетентности СО в осуществлении перспективного развития, так как вопросы связанные с обеспечением экономической надежности встают в противовес с главным принципом его деятельности.

Таким образом, в реформировании электроэнергетического комплекса отсутствует гармонизация его развития, западный опыт был перенесен без учета российской специфики. Поэтому проводимые изменения в электроэнергетике не оказали существенного влияния на показатели роста как отрасли, так и экономики в целом. Кроме того, имеющиеся кадровые и финансовые возможности ограничивают эффективность государственного управления в данной сфере.

1. Постановление правительства РФ от 27.12.96 №1569 «О первооче-редных мерах по реализации государственной стратегии экономической безопасности российской федерации (основных положений), одобренной указом президента российской федерации от 29 апреля 1996 г. №608» // Российская газета №13. - 1997. - 21 января.

2. Указ Президента РФ от 29.04.96 г. № 608 «О Государственной стратегии экономической безопасности Российской Федерации (Основных положениях)» // [Электронный ресурс] - Режим доступа: URL: http://www.kremlin.ru/acts/bank/9261 (дата обращения - 01.12.2016).

3. National Energy Security post 9/11 / United States Energy Association [Электронныйресурс]. - Режимдоступа: http://www.usea.org/USEAReport.pdf (датаобращения: 15.03.2016)

4. Борталевич С.И., Логинов Е.Л., Омарова 3.К. Мультиресурсное управление оборотом топливно-энергетических ресурсов в агрегированных энергообъединениях. - М.: Институт проблем рынка РАН, 2015.

5. Гордиенко Д.В. Основы экономической безопасности государства. // Курс лекций: учеб.-метод. пособие. - М.: Финансы и статистика; ИНФРА-М, 2009. 224 с.

6. Грачёв И.Д., Некрасов С.А. Стратегический аспект энергетической безопасности России // Национальные интересы: приоритеты и безопасность. 2012. № 41. С. 2-9.

7. Дробышевская Л.Н., Аведисян Н.Н., Мироненко Н.В. Россия: про-шлое, настоящее, будущее // Национальные интересы: приоритеты и безопас-ность. 2009. № 16. С. 10-15.

8. Дробышевская Л.Н., Ивахненко А.В. Формирование системы управления инновационной деятельностью электроэнергетических компаний России //Региональная экономика: теория и практика. 2010. № 13. С. 12-17. 